\title{
Perancangan Aplikasi Keamanan Teks Pada Algoritma Vigenere Chiper
}

\author{
Gyna Rahmi Fajri' ${ }^{1}$, Bayu Kurniawan ${ }^{2}$ \\ Program Studi Teknik Informatika Fakultas Ilmu Komputer Universitas Lancang Kuning \\ Jl. Yos Sudarso KM. 8 Rumbai, Pekanbaru, Riau, telp. 08117532015 \\ e-mail: gynarahmifajri@gmail.com, bayu.k18999@gmail.com
}

\begin{abstract}
Abstrak
Masalah keamanan merupakan salah satu aspek penting dari sebuah sistem informasi. Namun masalah keamanan ini seringkali kurang mendapat perhatian dari para pemilik dan pengelola sistem informasi. Kriptografi memiliki peranan yang besar dalam dunia keamanan data. Dengan adanya ilmu yang mempelajari bagaimana menjaga data agar tetap terahasia, diharapkan dapat menciptakan rasa aman bagi siapapun yang ingin menyimpan dan merahasiakan data mereka. Aplikasi yang dibangun ini dapat mengenkripsi file (plaintext) dalam bentuk teks. Enkripsi dilakukan dengan menggunakan kunci tertentu, sehingga menghasilkan chipertext (file yang sudah dienkrip atau disandikan) yang tidak dapat dibaca ataupun dimengerti. Ciphertext tersebut dapat dikembalikan seperti semula jika didekripsi menggunakan kunci yang sama sewaktu mengenkripsi file tersebut. Perangkat lunak yang digunakan untuk User-System Interface-nya adalah Netbeans 8.2. Sistem keamanan file merupakan sistem yang diperlukan bagi setiap lembaga atau organisasi, sehingga keberadaan sistem kemanan file menjadi penting untuk melindungi sebuah teks penting agar data tersebut terjaga dari pihak-pihak yang tidak berkepentingan. Dalam pembuatan aplikasi kriptografi ini, metode yang digunakan adalah Vigenere Cipher.
\end{abstract}

Kata Kunci : Kriptografi, Vigenere Chiper, Netbeans

\section{Abstract}

The issue of security is one of the important aspects of an information system. However, this security problem is often not getting the attention of the owners and managers of information systems. Cryptography has a large role in the world of data security. With the knowledge that studies how to keep data confidential, it is expected to create a sense of security for anyone who wants to keep and keep their data confidential. This built application can encrypt files (plaintext) in the form of text. Encryption is done by using certain keys, so that it produces ciphertext (encrypted or encrypted files) that cannot be read or understood. The ciphertext can be returned to normal if decrypted using the same key when encrypting the file. The software used for the User-System Interface is Netbeans 8.2. File security system is a system that is needed for every institution or organization, so the existence of a file security system is important to protect an important text so that the data is protected from unauthorized parties. In making this cryptographic application, the method used is Vigenere Cipher.

Keywords: Cryptography, Vigenere Chiper, Netbeans 


\section{PENDAHULUAN}

Di era globalisasi ini, dimana segala sesuatunya itu berjalan dengan cepat, kemajuan teknologi semkain memudahkan manusia untuk berkomunikasi dan saling bertukar informasi. Tetapi dengan kemajuan teknnologi itu pula dapat mengakibatkan informasi yang ditukar bisa terganggu dan biasanya dapat di ubah oleh orang lain yang tidak berhak.

Pada masa saat ini sistem infomasi dan komunikasi semakin berkembang pesat. Untuk kebutuhan manusia, Hal ini yang mempengaruhi tingkat keaman informasi pada teknologi. Yang mana tidak memerlukan kabel saat ini bisa menggunakan non cabel yang menggunakan udara dan dapat memindahkan dengan mudah. Pengguna media memungkinkan pihak tidak berkepentingan melihat bahkan mengisi data tersebut yang akan merusak integrasi data, terutama yang bersifat rahasia. Maka oleh sebab itu di butuhkan aplikasi yang bisa merubah data sehingga tidak mudah di lihat atau di ubah oleh pihak yang tidak berkepentingan.

Pada zaman yang lebih modern, ilmu keamanan data ini sudah dikenal dengan kriptografi. Pada masa data telah diolah dengan komputer (secara komputerisasi), kriptografi juga ikut berkembang. Kriptografi yang sebelumnya hanya diterapkan secara tradisional, kini sudah berkembang dengan melibatkan perhitungan matematika dan teori bilangan dalam pembangkitan kunci, proses enkripsi dan dekripsinya. Walaupun begitu, kriptografi klasik atau yang dikenal dengan kriptografi klasik masih banyak digemari oleh kriptografer karena kesederhanaannya dalam enkripsi dan dekripsi pesan.

Kriptografi adalah ilmu yang mempelajari teknik-teknik matematika yang berhubungan dengan aspek keamanan informasi seperti kerahasiaan, integritas data, serta otentikasi. Ilmu sandi (kriptografi) sendiri telah ada sejak lama. Tercatat dalam sejarah bahwa Julius Caesar, seorang kaisar Romawi menggunakan penyandian untuk menyampaikan pesan rahasia saat perang.

Sandi Vigenère sebenarnya merupakan pengem-bangan dari sandi Caesar. Pada sandi Caesar, setiap huruf teks terang digantikan dengan huruf lain yang memiliki perbedaan tertentu pada urutan alfabet. Misalnya pada sandi Caesar dengan geseran 3, A menjadi D, B menjadi E and dan seterusnya. Sandi Vigenère terdiri dari beberapa sandi Caesar dengan nilai geseran yang berbeda. Untuk menyandikan suatu pesan, digunakan sebuah tabel alfabet yang disebut tabel Vigenère, tabel Vigenère berisi alfabet yang dituliskan dalam 26 baris, masing-masing baris digeser satu urutan ke kiri dari baris sebelumnya, membentuk ke-26 kemungkinan sandi Caesar. Setiap huruf disandikan dengan menggunakan baris yang berbeda-beda, sesuai kata kunci yang diulang. Sandi ini dikenal luas karena cara kerjanya mudah di-mengerti dan dijalankan, dan bagi para pemula sulit dipecahkan.

\section{Metode Penelitian}

Metodologi penelitian dan kerangka kerja penelitian yang digunakan merupakan langkah-langkah yang akan dilakukan dalam rangka penyelesaian masalah yang akan dibahas. Adapun tahapan-tahapan kerangka kerja yang dibutuhkan dalam penyusunan penelitian ini dapat dilihat seperti gambar 1 . 
Gambar 1. Metode Penelitia

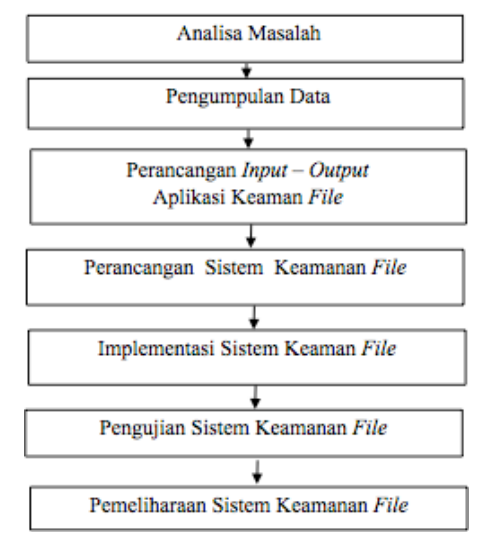

\section{Analisa Masalah}

Langkah analisis masalah adalah untuk dapat memahami masalah yang telah ditentukan ruang lingkup dan batasannya. Dengan menganalisa masalah yang telah dilakukan tersebut, maka diharapkan masalah dapat dipahami dengan baik. Teknik analisis yang digunakan dengan beberapa tahap berikut :

1. Tahap identify yaitu : mengidentifikasi permasalahan yang terjadi

2. Tahap understand yaitu : memahami lebih lanjut tentang masalah yang ada dengan cara melakukan pengumpulan data yang diperlukan.

Tahap analyze yaitu : mencari kelemahan-kelemahan sistem yang ada dan mengumpulkan informasi tentang kebutuhan-kebutuhan lebih lanjut yang diperlukan oleh pemakai

\section{Pengumpulan Data}

Untuk mendukung penelitian ini, salah satu penunjangnya adalah data, Dalam tahap pengumpulan data berupa teks yang akan dienkripsi.

\section{Perancangan Input - Output Aplikasi Keamanan File}

Pada tahapan ini merancang input - output dengan menggunakan bahasa pemograman Netbeans 8.2 dengan menggunakan tool pada program tersebut.

\section{Perancangan Sistem Keamanan File}

Pada tahapan ini merancang sistem keamanan file dengan menggunakan metode algoritma Vigenere Chiper bahasa pemograman Java.

\section{Implementasi Sistem Keaman File}

Pada tahap ini penulis mengimplementasikan sistem keamanan file dengan menjalankan aplikasi untuk enkripsi pada teks.

\section{Pengujian Sistem Keamanan File}

Pada tahapan ini penulis melakukan pengujian dengan menggunakan teks penting.

\section{Pemeliharaan Sistem Keamanan File}


Pada tahap ini penulis melakukan pemeliharaan sistem keamanan file terkait penggunaan sistem dan kesalahan-kesalahan yang terjadi selama penggunaan sistem.

\section{Hasil dan Pembahasan}

Hasil dan pembahasan dibagi menjadi beberapa tahapan berikut.

\section{Bagan Alir Sistem Aplikasi}

Bagan alir sistem aplikasi ini menjelaskan proses yang terjadi pada aplikasi yang dibuat secara keseluruhan. Pada bagan alir sistem aplikasi ini akan digambarkan bahwa data yang diinputkan pada aplikasi berasal dari satu sumber, yaitu dari harddisk ataupun media penyimpanan lainnya. Sebelum proses input file, user harus memilih instruksi (menu) yang akan digunakan untuk memproses file (enkripsi/dekripsi). Bagan alir sistem dapat dilihat pada gambar 2 .

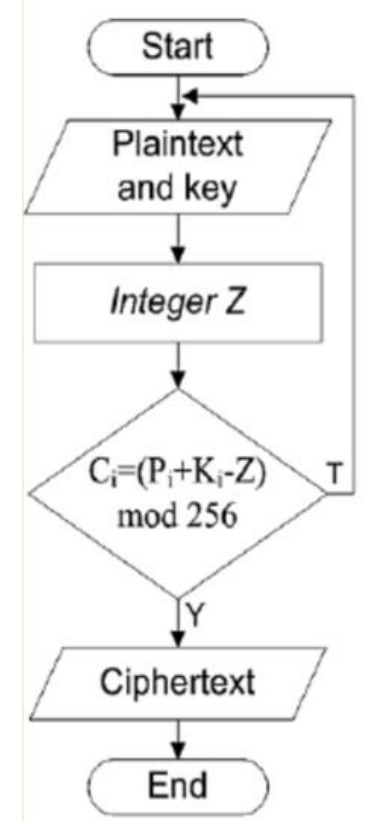

Gambar 2 Flowchart Proses Enkripsi 


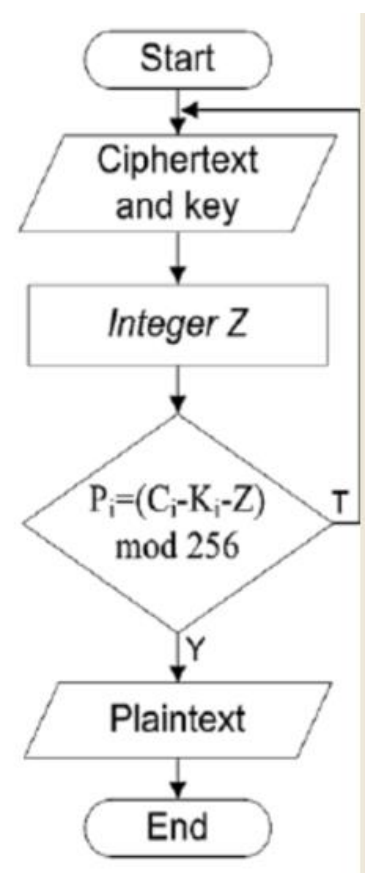

\section{Gambar 2.1 Gambar Proses Deskripsi}

\section{Desain Interface}

Program berinteraksi dengan pengguna melalui layar tampilan dalam bentuk jendela (window). Layar tampilan menampilkan informasi yang berbeda-beda tergantung pada perintah yang diberikan oleh pengguna. Program ini diberi nama Kriptofile. Program ini memiliki beberapa tampilan, beberapa rancangan layar tampilan tersebut adalah pada gambar 3.

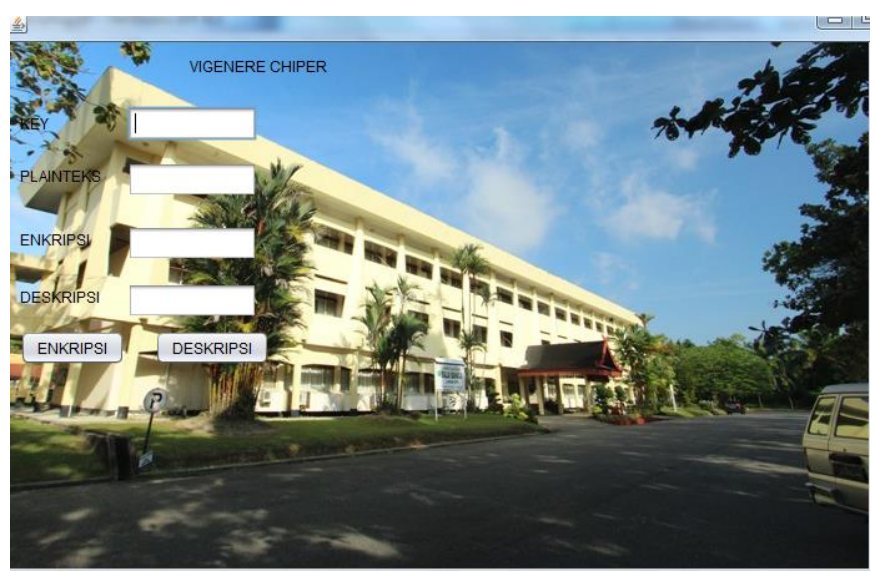

Gambar 3. Form Menu Utama

Tampilan utama aplikasi yang dibuat terlihat seperti pada gambar 3 di atas. Pada tampilan utama ini terdapat beberapa menu dan dari beberapa menu ini juga terdapat beberapa sub menu seperti sub menu enkripsi yang di gunakan untuk mengenkripsi sebuah teks, menu kriptografi terdapat dua sub sub menu dekrip untuk menampilkan form dekrip.

\section{Hasil Enkripsi dan Deskripsi}


Pada gambar 4 terlihat hasil enkripsi dengan memasukan kunci dan plainteks

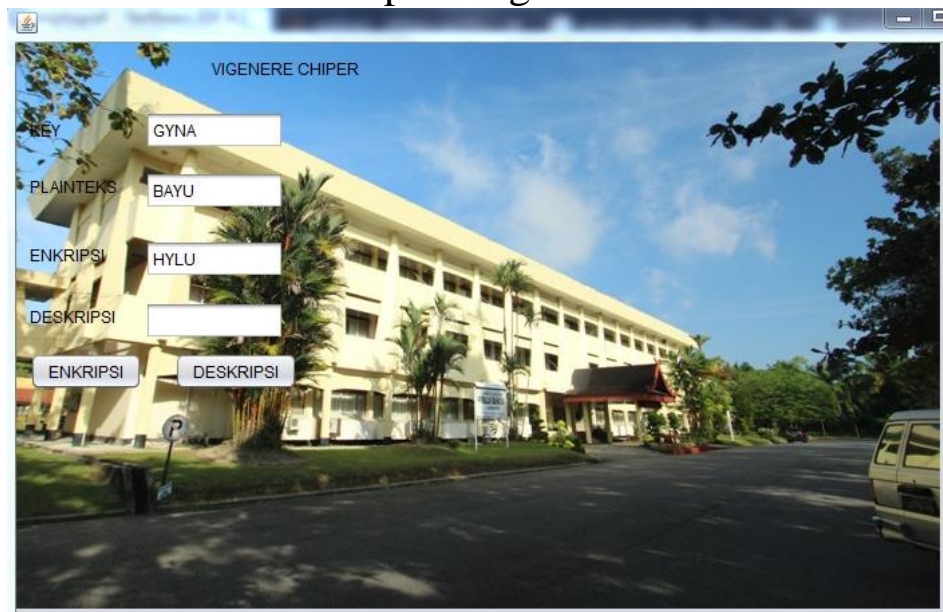

Gambar 4. Hasil Enkripsi

Pada gambar 4.1 terlihat hasil deskripsi dengan klilk tombol deskripsi yang otomatis lansung muncul hasilnya

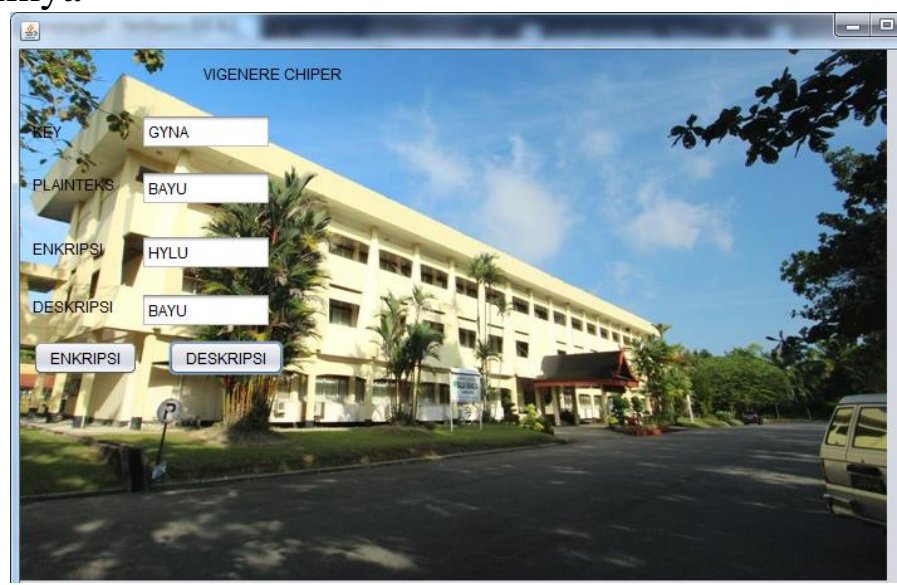

Gambar 4.1. Hasil Deskripsi

\section{Koding dari algoritma Vigenere Chiper}

a. Enkripsi

String res = "";

text $=$ text.toUpperCase () ;

for (int $\mathrm{i}=0, \mathrm{j}=0 ; \mathrm{i}<$ text.length ()$; \mathrm{i}++)\{$

char $\mathrm{c}=$ text.charAt(i);

if $(\mathrm{c}<$ 'A' ||$c>$ ' $\mathrm{Z}$ ') continue;

res $+=(\operatorname{char})\left(\left(\mathrm{c}+\mathrm{key} \cdot \operatorname{charAt}(\mathrm{j})-2 *{ }^{\prime} \mathrm{A}\right.\right.$ ') $\left.\% 26+{ }^{\prime} \mathrm{A}\right)$;

$\mathrm{j}=++\mathrm{j} \%$ key.length();

\}

return res; 


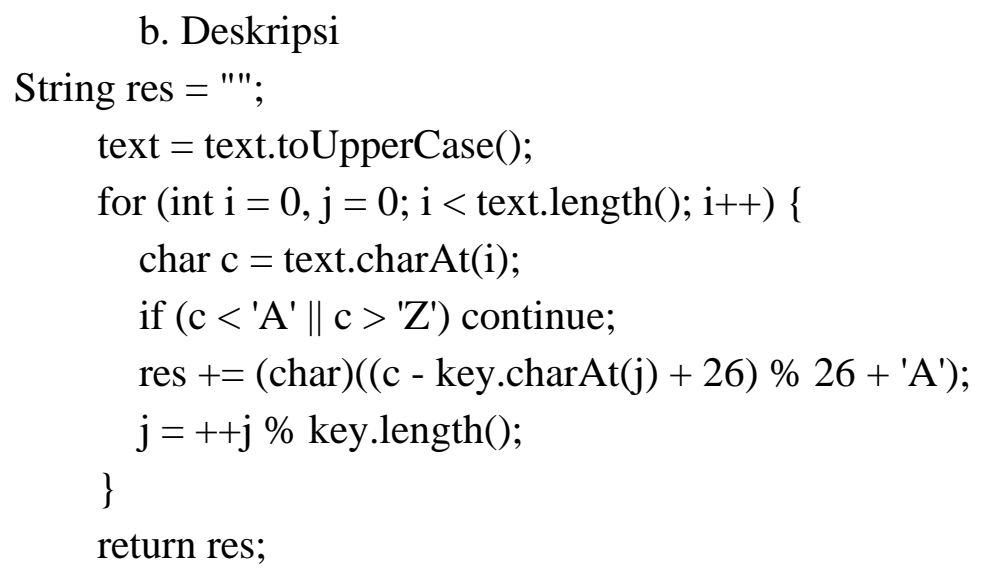

\section{Kesimpulan}

Setelah melakukan penelitian dan perancangan aplikasi sistem keamanan teks algoritma Vigenere Chiper, maka dapat diambil beberapa kesimpulan sebagai berikut :

1. Aplikasi keamanan file ini masih mengamankan data teks.

2. Aplikasi keamanan file ini menggunakan perancangan SDLC dan implementasi dengan pemograman Netbeans 8.2 menggunakan java.

Berdasarkan hasil penelitian yang dilakukan untuk pengamanan teks, saran untuk penerapan dan kelanjutan sistem ini adalah :

1. Bagi para peneliti yang ingin mengembangkan sistem keamanan teks dengan algoritma Vigenere ini dapat dikembangkan lagi menjadi lebih baik dengan melengkapi dan menambah jenis file yang akan diamankan.

2. Bagi para peneliti harus mengembangkan aplikasi tersebut seperti menambah file untuk dienkripsi atau di deskripsi

3. Bagi para peneliti yang ingin mengembangkan sistem keamanan teks lebih baik lagi dengan algoritma yang lebih baik dalam hal penerapan keamanan serta handal dari perusak dokumen melalui jaringan online.

\section{Daftar Pustaka}

1 Nurliana Nasution, Ahmad Zamsuri, Khairani Djahara. Aplikasi Keamanan File Algoritma Blowfish pada Universitas Lancang Kuning. Jurnal Teknologi Informasi \& Komunikasi Digital Zone, Volume 6, Nomor 1, Mei 2015: 10-16

.2. Marsel Fio Ipandi, Arzi Al Hafiz, Afriliansyah, M.Aldi Febrian, Mhd. Arief Hasan. PENERAPAN ALGORITMA KRIPTOGRAFI ASIMETRIS DENGAN METODE RSA DAN BLOWFISH UNTUK ENKRIPSI DAN DESKRIPSI GAMBAR MENGGUNAKAN JAVA NETBEANS JURNAL TEKNOLOGI INFORMASI DAN KOMUNIKASI January 2020.

3. Muhammad Dedi Irawan. IMPLEMENTASI KRIPTOGRAFI VIGENERE CIPHER DENGAN PHP. JURNAL TEKNOLOGI INFORMASI (JurTI)Volume 1, Nomor 1, Juli 2017 
4. Muhammad Khoiruddin Harahap. ANALISIS PERBANDINGAN ALGORITMA KRIPTOGRAFI KLASIK VIGENERE CIPHER DAN ONE TIME PAD. Jurnal Nasional Informatika dan Teknologi Jaringan

5. Efrandi, Asnawati, Yupiyanti. APLIKASI KRIPTOGRAFI PESAN MENGGUNAKAN ALGORITMA VIGENERE CIPHER. Jurnal Media Infotama Vol. 10 No. 2

6. Erwin Gunadhi, Agung Sudrajat. PENGAMANAN DATA REKAM MEDIS PASIEN MENGGUNAKAN KRIPTOGRAFI VIGÈNERE CIPHER. Jurnal Algoritma Sekolah Tinggi Teknologi Garut 